Article

\title{
Self-Tuning High-Voltage and High-Frequency Sinusoidal Power Supply for Dielectric Barrier Discharge Plasma Generation
}

\author{
Gabriele Neretti ${ }^{D}$ and Mattia Ricco *(D) \\ Electric Electronic and Information Engineering Department, University of Bologna, Viale Risorgimento 2, \\ 40136 Bologna, Italy; gabriele.neretti@unibo.it \\ * Correspondence: mattia.ricco@unibo.it
}

Received: 25 September 2019; Accepted: 4 October 2019; Published: 8 October 2019

\begin{abstract}
In this paper a high-voltage sinusoidal power supply controlled by Arduino DUE micro-controller is described. This generator can feed a dielectric barrier discharge (DBD) load with sinusoidal voltages up to $20 \mathrm{kV}$ peak and frequencies in the range 10-60 kHz, with a maximum output power of $200 \mathrm{~W}$. Output voltage can be produced either in a continuous mode, or with on/off modulation cycles, according to treatment/application requirements. This power source is equipped with on-board diagnostics used to measure the output voltage and the charge delivered to the load. With a sample frequency of $500 \mathrm{kHz}$, Arduino DUE allows to evaluate both the high voltage and the average power feeding the discharge without the use of an expensive external measurement setup. Lissajous techniques are utilized to calculate discharge average power in a quasi-real-time manner. When a load is connected to high-voltage terminals, a self-tuning procedure is carried out to obtain the best working frequency. This parameter allows to minimize power-electronic component stress and to maximize generator efficiency.
\end{abstract}

Keywords: high-voltage generator; non-thermal plasma; dielectric barrier discharge; self-tuning frequency; high-voltage on-board diagnostics

\section{Introduction}

Non-thermal atmospheric pressure plasmas are intensively investigated and used in a wide range of research fields and industrial domains such as in aeronautics and aerospace, surface treatment processes, air and water pollutant abatement and biomedical applications [1-7]. Dielectric barrier discharges (DBDs) are often used as non-thermal plasma sources because they allow the generation of a homogeneously distributed non-thermal plasma at atmospheric pressure in a cheap way. Furthermore, they are easy to build in a multitude of geometries and can be easily scaled up [1]. A DBD reactor is made by two electrodes separated by one or more dielectric layers [8]. Several reactor geometries have been investigated in the last decades [9]. In this work, two of the most commonly used reactor geometries have been employed to test the generator: the volumetric discharge with hemispherical plates and the surface discharge. Reactor sketches and corresponding generated discharges are displayed in Figure 1. When a variable voltage, with high enough amplitude, is applied to the electrodes, the gas breakdown occurs. The representative voltage-current characteristic of a sinusoidal supplied DBB load is presented in Figure 2a. 

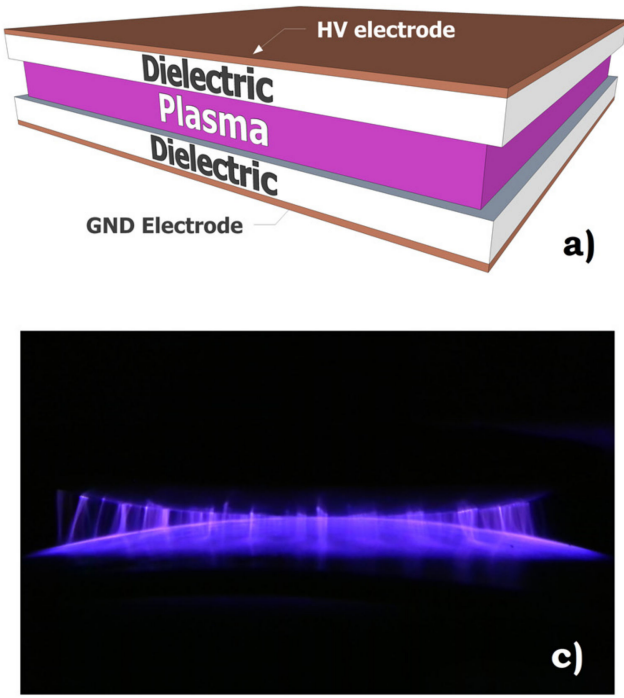
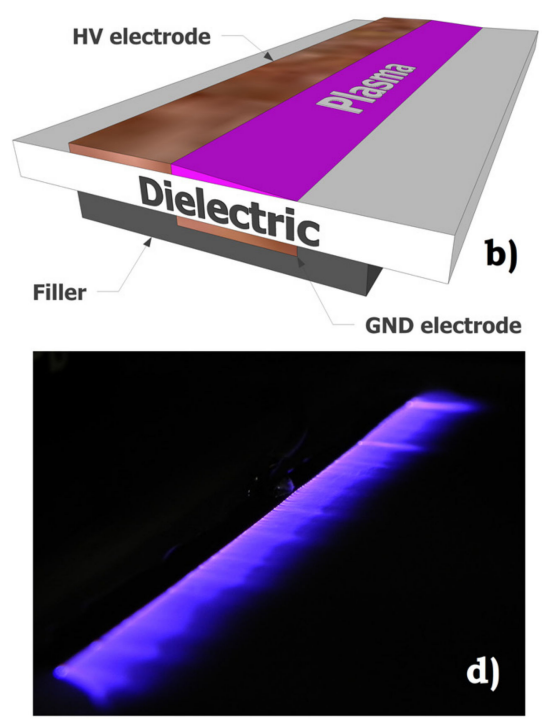

Figure 1. Typical (a) volumetric and (b) surface reactor sketches and corresponding images of a volumetric discharge with (c) hemispherical electrodes and (d) a surface dissymmetric discharge.
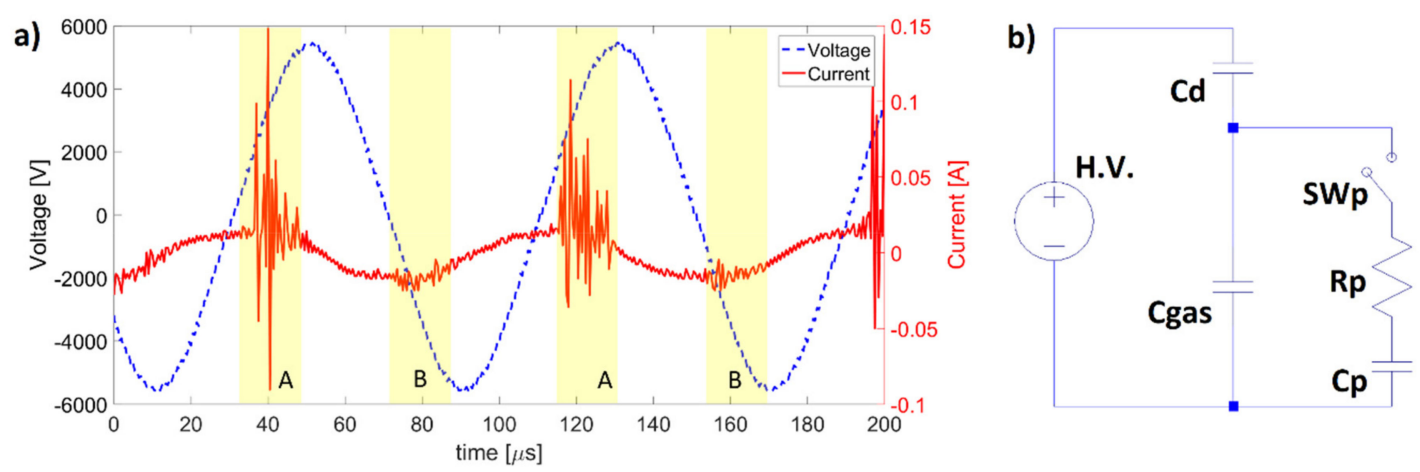

Figure 2. Dielectric barrier discharges (DBDs): (a) voltage-current time behavior and (b) equivalent electrical circuit.

Plasma is macroscopically ignited twice each voltage period (A and B intervals highlighted in light yellow in the figure [10]. Within each of these time intervals, the plasma with a streamer nature appears (the red line of the current is no more sinusoidal in these intervals). Streamer (which is a plasma filament) repetition rate is usually in the range from 1 to $10 \mathrm{MHz}$ with lifetimes of few tens of nanoseconds [1]. A simplified equivalent circuit of a DBD is presented in Figure $2 \mathrm{~b}$ where $C_{d}$ and $C_{g a s}$ are equivalent capacities of dielectric and gas gaps, respectively. The switch $S W_{p}$ is closed every time a plasma streamer is formed (i.e., in the $\mathrm{MHz}$ range). The presence of the plasma resistance $R_{p}$ reflects average power used by the discharge to ionize the gas, the plasma capacity $C_{p}$ takes into account the increase in the overall reactor capacity when the plasma is ignited [1]. This equivalent circuit is strongly capacitive with power factors typically below 0.05 .

In plasma medicine applications, surface modification and chemical activation due to the plasma effect is strongly energy-dose-dependent [11]. Thus, the knowledge of the average power feeding the discharge is a crucial parameter to be evaluated. Moreover, when a high amount of power is requested (as an example in ozone generation for air or water sanification [12]), the efficiency of the high-voltage power supply must be considered too. In this way an environmentally friendly process is achieved.

Several power supply typologies used to feed DBD loads have been presented in the last decade. Sinusoidal [1], pulsed [11-14] and arbitrary voltage waveforms $[15,16]$ are the most used ones. Due to the low cost and robustness, sinusoidal power sources are frequently preferred. AC power supplies are usually constituted by a low-voltage section and a step-up transformer. The discharge can be ignited directly at the net frequency $(50$ or $60 \mathrm{~Hz}$ ) [17], or at increased frequencies, by using power electronic 
components. Several architectures with one [18], two [19] or four [20] electronic switches have been utilized. Transformer-less configurations have been used as well [21].

In this paper a high-voltage power supply based on a push-pull converter, controlled by an Arduino DUE micro-controller and equipped with on-board diagnostic is presented. This voltage source is used to produce DBD non-thermal discharges at atmospheric pressure with a self-tuned working frequency. The self-tuning depends on the load impedance and guarantees a high efficiency and a low wear of the components. Output voltage and average power delivered to the discharge are detected and monitored in a quasi-real-time way without the use of an expensive external measurement setup. This power source allows to supply the load continuously or with on/off modulation cycles. An optimization of these voltage waveform trains is usually crucial in aeronautics [22,23] and in treatment processes [24,25]. LTspice software [26] has been utilized to better understand the behavior of the generator and to compare experimental measurements and simulation results.

This paper is divided as follows. Firstly, the power supply architecture is presented in Section 2. Then, the reasons for using the Arduino 2 micro-controller are given. The average power measurements and basic generator operations are provided in Sections 4 and 5, respectively. The proposed self-tuning control strategy is described in Section 6. Finally, conclusions are given.

\section{Power Supply Architecture}

The supply source presented in this work can generate a sinusoidal high-voltage output up to $20 \mathrm{kV}$ peak with a variable frequency in the range between 10 and $60 \mathrm{kHz}$ with an output average power up to $200 \mathrm{~W}$. The generator architecture is based on a commercial low-voltage AC/DC converter feeding a push-pull high-voltage transformer (Figure 3). The commercial AC/DC converter is rated with voltages up to $40 \mathrm{~V}$ (VDC in Figure 3) and currents up to $10 \mathrm{~A}$. This typology of the DC power source has been chosen because of its robustness, availability on the market, and safety reasons.

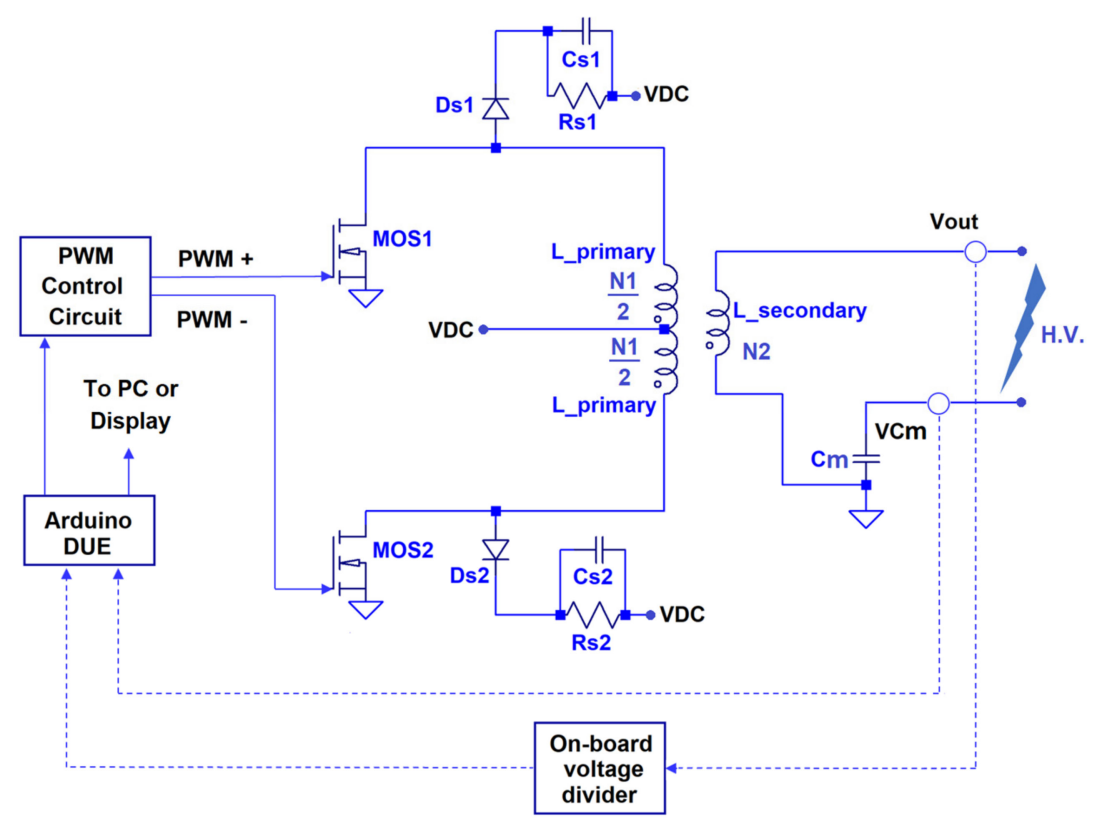

Figure 3. Electrical architecture of the supply source.

The PWM control signal is generated by a TL494 integrated circuit. IRF3415 MOSFETs have been utilized as switches. The micro-controller Arduino DUE is used both to regulate the switching frequency and to sample the two signals $V_{\text {out }}$ and $V_{C m}$. The former is varied by changing the value of a digital potentiometer connected to the oscillator frequency pin of the TL494 integrated circuit. The sampling circuit, the on-board voltage divider and the presence of the measurement capacitor $C_{m}$ shown in Figure 3 will be described later on. Each primary winding is constituted by 7 turns 
( $N_{1} / 2$ in the figure), the secondary one by 1000 turns ( $N_{2}$ in the figure). The high-voltage winding is a commercial one, and it is insulated by means of a silicon rubber potting. The components $D_{s}, R_{s}$ and $C_{S}$ in Figure 3 constitute snubber circuits utilized to limit MOSFET overvoltages during commutations.

Another important feature of this power supply is the possibility to modulate the output voltage with on/off cycles. An example of on/off voltage modulation with on- and off times equal to 1 and $2 \mathrm{~ms}$ respectively, is presented in Figure 4. The plasma generation frequency has been set to $40 \mathrm{kHz}$. This means that for each on-time interval, 40 waveform cycles are generated. The figure shows a transient of about $500 \mu$ s after the switching-on phase and an almost negligible one after the switching-off phase. As already mentioned, this modulation strategy is a key-role parameter in several research and industrial applications to achieve both effective and efficient treatments.

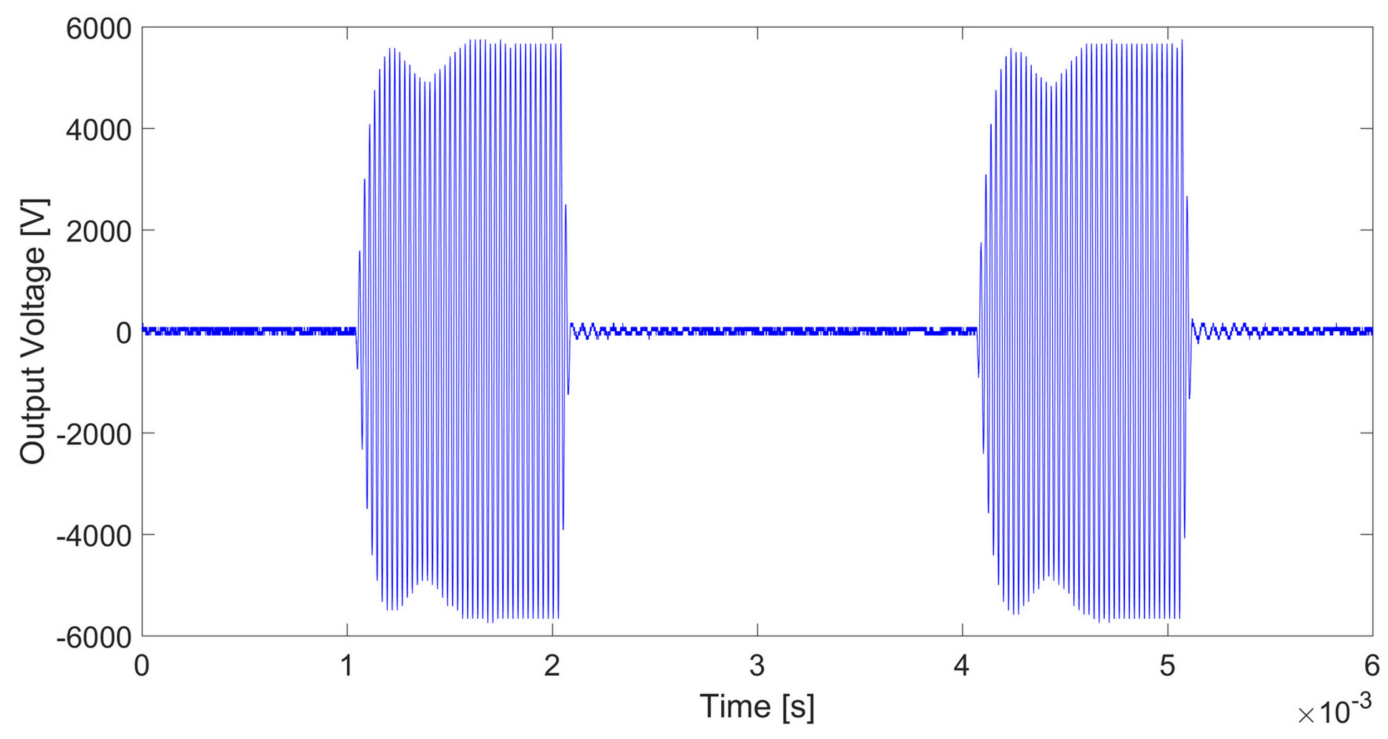

Figure 4. Example of on/off output voltage modulation with $1 \mathrm{~ms}$ "on" and $2 \mathrm{~ms}$ "off".

\section{Reasons for Using Arduino DUE Micro-Controller}

The main features of this supply system are its flexibility, the possibility to visualize output voltage and average power feeding the discharge, and to self-detect and tune the best working frequency depending on the load connected to it. As will be described in the following, the working frequency allows both to maximize generator efficiency and to decrease MOSFETs' electrical stress. Arduino DUE has been chosen because it is a low-cost micro-controller, able to detect analog signals with a sample rate frequency up to $500 \mathrm{kHz}$. As far as the maximum output frequency is $60 \mathrm{kHz}$, according to the Nyquist-Shannon sampling theorem, a $500 \mathrm{kHz}$ sample rate guarantees a correct sampling of the signal up the fourth harmonic. For lower working frequencies this condition can be fulfilled even for a higher harmonic content.

The high-voltage signal $V_{\text {out }}$ is detected by means of an on-board resistive divider capacitively compensated and sampled by the micro-controller. This voltage divider is constituted by the series of 20 high-voltage resistors, each one rated with $2 \mathrm{M} \Omega, 3 \mathrm{kV}$. The measurement resistor, in series with the other 20 high-voltage ones, is connected to the ground terminal and it is rated with $1.5 \mathrm{k} \Omega, 100 \mathrm{~V}$. Each high-voltage resistor has in parallel a high-voltage capacitor, $220 \mathrm{pF}, 3 \mathrm{kV}$. The measurement resistor has in parallel a $15 \mathrm{pF}, 100 \mathrm{~V}$ capacitor.

The average power $\mathrm{P}$ feeding the discharge is given by:

$$
P=\frac{1}{T} \int_{0}^{1 / T} v_{\text {out }}(t) i_{\text {out }}(t) d t
$$

where $\mathrm{T}$ is the waveform period and $v_{\text {out }}$ and $i_{\text {out }}$ are the voltage and current feeding the load, respectively. 
The harmonic content of the plasma current feeding a DBD reactor is typically in the range between 1 and $10 \mathrm{MHz}$ (see [1] and Figure 2a). Thus, a correct evaluation of the average power feeding the discharge must be done by using both a current probe and an analog/digital converter with an appropriate bandwidth reasonably higher than $10 \mathrm{MHz}$. In order to contain the costs of the generator, the average power has been evaluated by using the Lissajous charge-voltage figures [27]. The charge measurement is done by means of the insertion of a shunt capacitance $\left(C_{m}\right.$ in Figures 3 and $\left.5 \mathrm{a}\right)$ in series with the load. The capacitance must be several orders of magnitude higher than the reactor capacitance so that its influence on the voltage across the discharge gap is negligible. For this reason, a value of $10 \mathrm{nF}$ has been chosen. The charge $q_{m}$ accumulated by the $C_{m}$ capacitor can be expressed by using the capacitor voltage drop $V_{C m}$ as $q_{m}=C_{m} V_{C m}$. By considering that the current feeding the load is $i_{\text {out }}=C_{m} \frac{d v_{C m}}{d t}$, Equation (1) can be expressed as:

$$
P=\frac{1}{T} \int_{0}^{1 / T} v_{\text {out }}(t) C_{m} \frac{d v_{C m}}{d t} d t==\frac{1}{T} \int_{0}^{1 / T} v_{\text {out }}(t) d q_{m}
$$

The last integral represents the energy delivered to the discharge in one waveform cycle and can be calculated as the area enclosed by the $V_{\text {out }}-Q_{m}$ curve in the Lissajous diagram. As far as this is an integral method, the requested sample rate is the same used for the applied voltage $V_{\text {out }}$. Thus, the micro-controller can be used to evaluate the average power when the Lissajous figure technique is used. In Figure 5b, an example of Lissajous figure is displayed. Regions " $A$ " and " $B$ " correspond to the time intervals in which the discharge is ignited (see Figure 2a). As far as the slope of the Lissajous curve is equal to the equivalent capacitance of the load, it is possible to note that the equivalent capacitance of the reactor when the discharge is ignited (" $\mathrm{A}$ " and " $\mathrm{B}$ " intervals), is about twice the equivalent capacitance without the presence of plasma. This behavior was already introduced when the equivalent discharge circuit was introduced in Figure $2 b$.
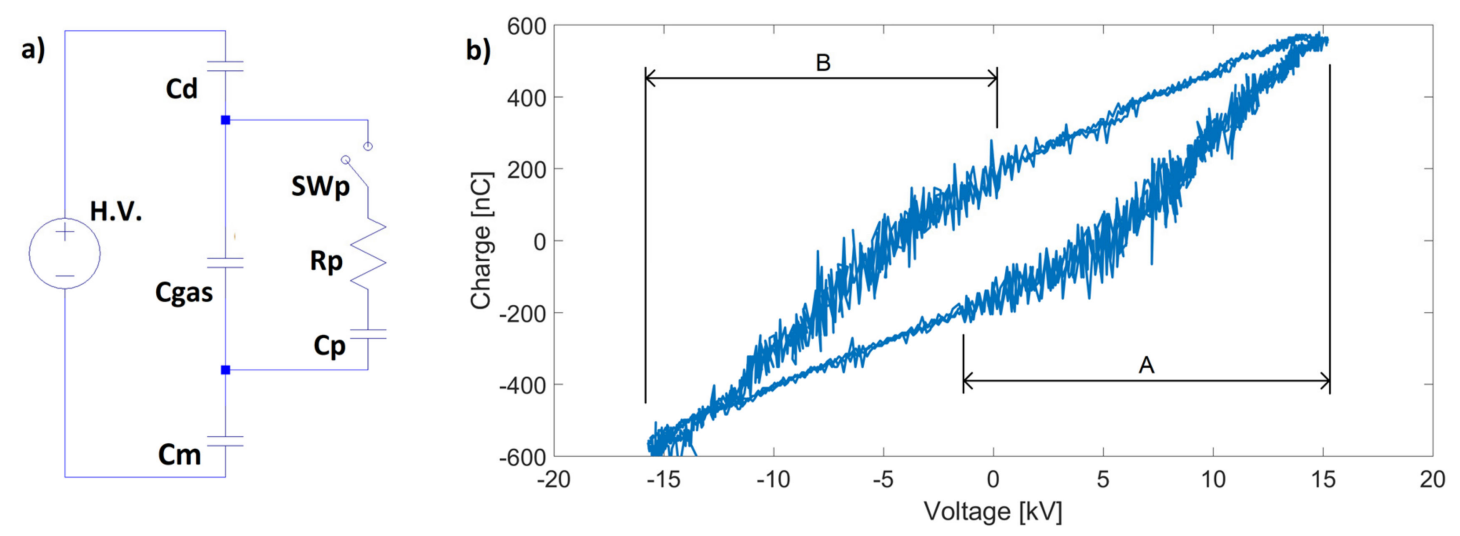

Figure 5. (a) DBD equivalent electric circuit with the presence of measurement capacity $\mathrm{Cm}$ and (b) Lissajous figure used for the average power calculation.

The creation of the on/off output voltage modulation (see Figure 4) is controlled by the micro-controller, inhibiting the TL494 PWM generation. The main information of working frequency, maximum output voltage, average power and on- and off-time intervals of the output modulation are available onto an on-board display or directly in a PC monitor.

\section{Average Power Measurements}

A series of measurements has been carried out to test the reliability of the average power evaluation performed by the micro-controller. The average power feeding the volumetric reactor has been calculated with the Q-V Lissajous technique, both by means of the micro-controller coupled with 
the generator on-board diagnostics, and by using a dedicated measurement setup. This is constituted by a Tektronix P6015 capacitively compensated high-voltage probe with a bandwidth up to $75 \mathrm{MHz}$ to measure the high-voltage signal and a Yokogawa low-voltage probe with $75 \mathrm{MHz}$ bandwidth to measure the voltage drop across $C_{m}$ capacity. Both signals have been acquired by a Yokogawa DL1740 4-channel, $500 \mathrm{MHz}$ bandwidth, $1 \mathrm{GS} / \mathrm{s}$ oscilloscope. In Figure 6 the high voltage and charge supplying the DBD reactor as a function of time, acquired by the micro-controller, are shown. In this example the switching frequency has been set to $25 \mathrm{kHz}$. As far as the sample rate is $500 \mathrm{kHz}$, each waveform period is acquired by means of 20 samples.

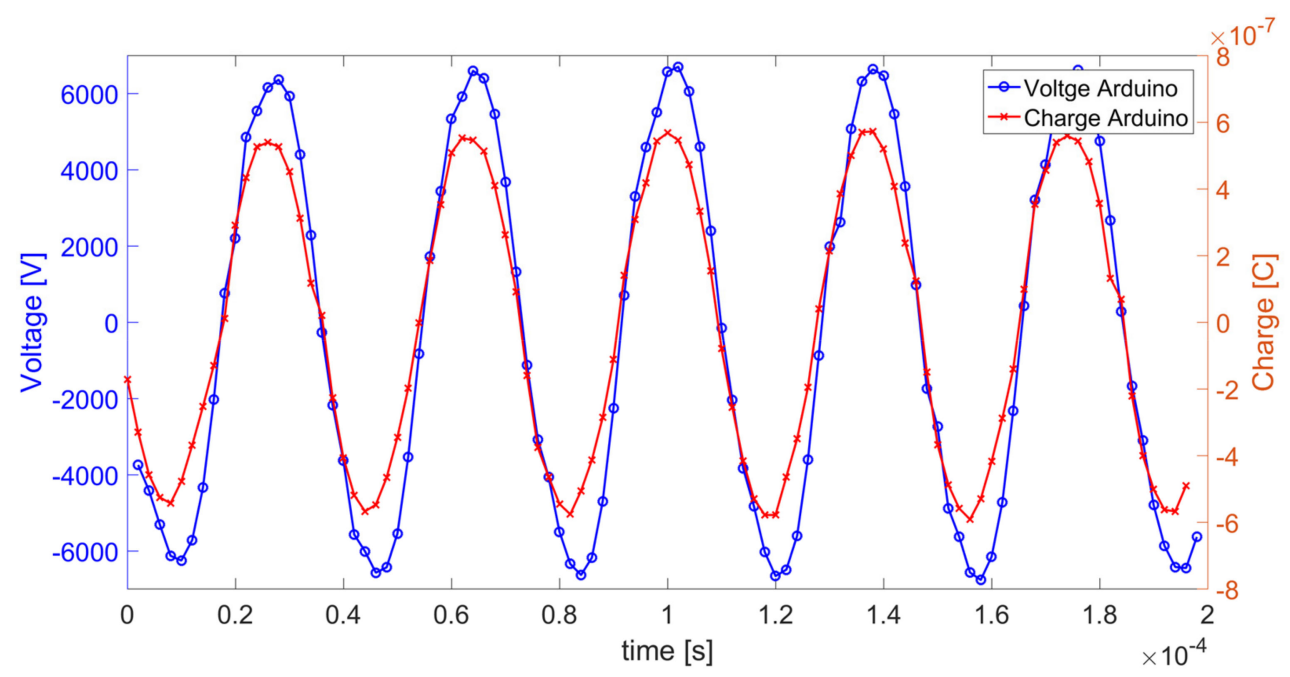

Figure 6. Voltage and charge as functions of time, detected by the micro-controller.

Charge and voltage of Figure 6 are used to evaluate the average power by means of the Q-V Lissajous technique. Lissajous curves obtained with the data presented in Figure 6 compared with those detected by means of the dedicated measurement setup are displayed in Figure 7. Curves are very similar and average powers calculated for the two setups by using Equation (2) differ by $4 \%$. This value is within the standard deviation error of $5 \%$, confirming the possibility to obtain a reliable average power measurement with the generator on-board diagnostics coupled with the micro-controller.

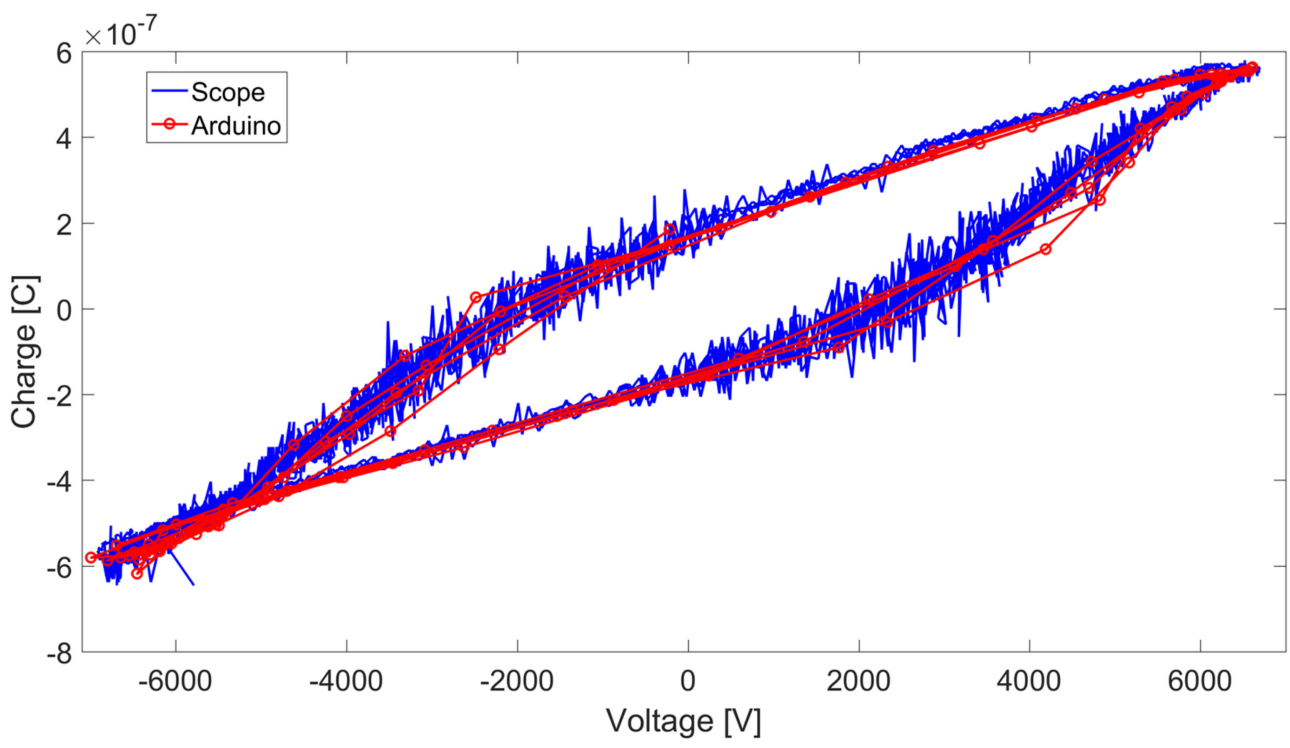

Figure 7. Q-V Lissajous figures detected by means of the dedicated measurement setup (continuous blue line) and by means of the micro-controller (red line with circles). 


\section{Basic Generator Operations}

In DBD plasmas working at several kilovolts and several tens of $\mathrm{kHz}$, the discharge regime is not strictly related with the value of the supplying frequency, because the streamer generation frequency is always in the megahertz range, with the plasma filament life-time of the order of tens of nanoseconds [1]. Supplying frequency mostly influences the number of periods per second in which plasma occurs. The most important parameter related to discharge effects is usually the average power feeding the discharge. An example is given by the ozone production obtained through a DBD plasma discharge. The ozone yield remains practically the same in the frequency range between 10 and $50 \mathrm{kHz}$. Working at constant voltage, a frequency increase leads to a higher discharge power and an increment of the ozone generated, keeping constant the energy cost for the ozone production $[10,12]$. In the aeronautics field, the same induced velocity can be obtained by using a DBD plasma actuator fed with the same average power obtained with different voltage-frequency values [28]. Thus, the working frequency can be selected using criteria related to the best performance of the power source, subsequently adjusting the supplying voltage to obtain the desired average power. In the experiments presented in this work, the chosen frequency maximizes the power supply efficiency through its dependence on the load impedance and minimizes the wear of components.

The possibility to vary the switching frequency is an important feature of this supply source. By changing this parameter, both different commutation regimes of the MOSFETs and different supply voltage harmonic contents are obtained. When the DBD reactor is connected to the high-voltage terminals, the switching frequency can be varied to achieve a soft switching condition. In this regime a zero-current switching (ZCS) is obtained, strongly limiting the overvoltages of the MOSFETs and thus minimizing the power dissipation into the snubber circuits.

To better understand the behavior of the generator as a function of the switching frequency, LTspice software has been utilized. MOSFETs have been implemented by using the Spice model available in the International Rectifier website. The magnetic coupling between windings has been implemented by using the mutual inductance coefficient $K$. By following LTspice user manual this parameter can be calculated as:

$$
K=\sqrt{\left(L-L_{\text {leak }}\right) / L},
$$

where $L$ is the winding self-inductance and $L_{\text {leak }}$ is the leakage inductance between the windings considered. Self and leakage inductances have been measured for all windings by using an Asita AS250 impedance meter. A substantial symmetry has been found, leading to the definition of a $K$ value equal to 0.94 for all windings.

A first important aspect of this supply source is the dependence of the output voltage magnitude with respect to the switching frequency. This relation is shown in Figure 8 when volumetric and surface reactors are supplied. The equivalent capacitance of the volumetric reactor is $120 \mathrm{pF}$ and for the surface one is $15 \mathrm{pF}$. These values have been obtained by using the Asita AS250 impedance meter. Continuous lines refer to measurements done by means of the micro-controller, dashed lines are the LTspice simulation results.

Experimental results and simulations are in a very good agreement, underlying the validity of the simplified model used in LTspice. Depending on the load capacity, a different resonance frequency can be observed. As far as the transformation ratio of the transformer is about 143, at the resonance frequency the output voltage supplied by the generator strongly increases maintaining the same input DC voltage. As expected, by increasing the load capacitance both the resonance frequency and the output voltage decrease.

In Figure 9a a comparison between measurements and simulation results is shown. On the left-hand side low voltage quantities as MOSFET voltages and bus DC current are shown. On the right-hand side output voltage is presented. This comparison is carried out for frequencies less than, equal to and greater than the soft switching frequency $\left(f_{s s}\right)$, at a fixed input DC voltage equal to $10 \mathrm{~V}$ 
and a reactor capacitance of $15 \mathrm{pF}$. As it has been shown for the results in Figure 8, an overall good agreement between measurements and simulations have been obtained.

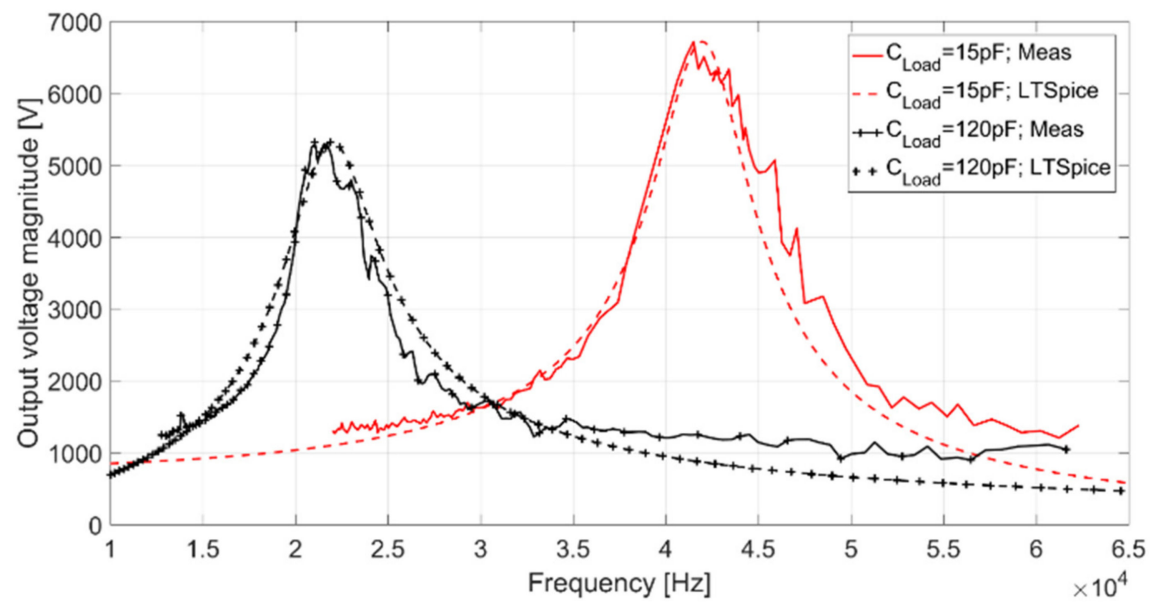

Figure 8. Comparison between measured and computed output voltages as a function of the switching frequency.

\section{a) $\mathbf{f}<$ fss}
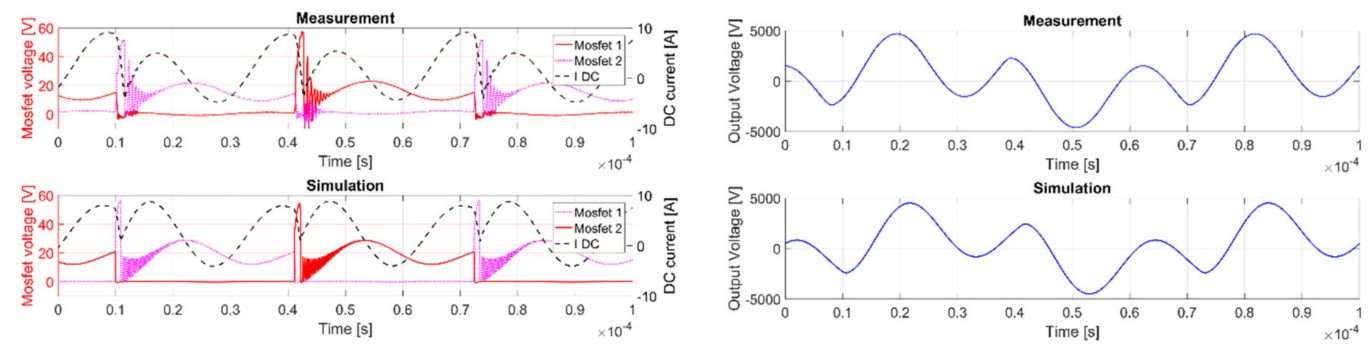

b) $f=$ fss
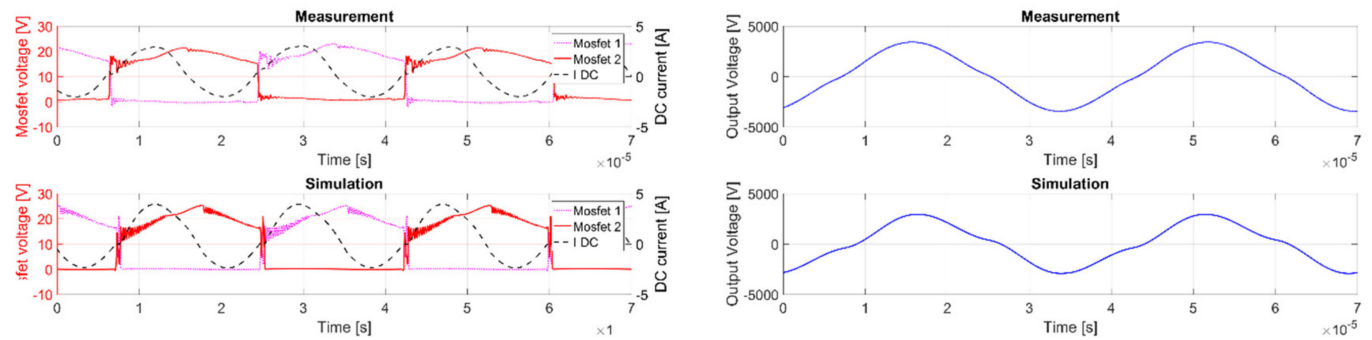

c) $f>$ fss
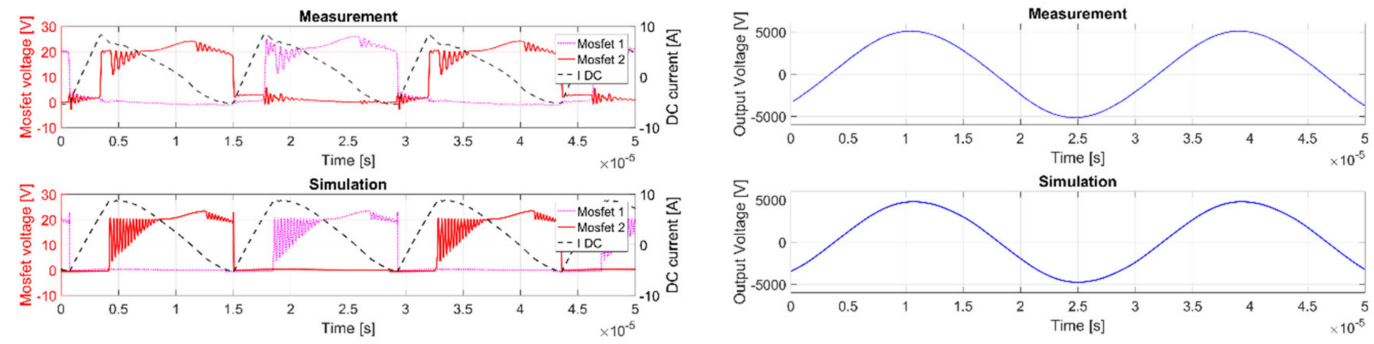

Figure 9. Comparison between measured and calculated MOSFET voltages, bus DC current (left-hand side) and output high voltage (right-hand side) for a frequency (a) less than the soft switching frequency; (b) equal to it; and (c) greater than it. 
For $f=f_{s S}$ (Figure 9b), MOSFET commutations take place when the bus DC current crosses zero (ZCS condition). Consequently, power dissipation during commutations is virtually avoided. Moreover, MOSFET overvoltages are minimized. For frequencies less than $f_{s S}$ (Figure $9 \mathrm{a}$ ) or greater than $f_{s s}$ (Figure 9c), the bus DC current is forced toward the zero value. This generates commutation losses into the MOSFETs and severe overvoltages that must be limited by snubber circuits. The overvoltages can exceed the regime value by several times. As an example, in Figure 10 the measured MOSFET voltages with and without the snubber circuit, for a frequency less than the soft switching value are plotted. Without the snubber circuit the overvoltage is about 5 times the regime value.

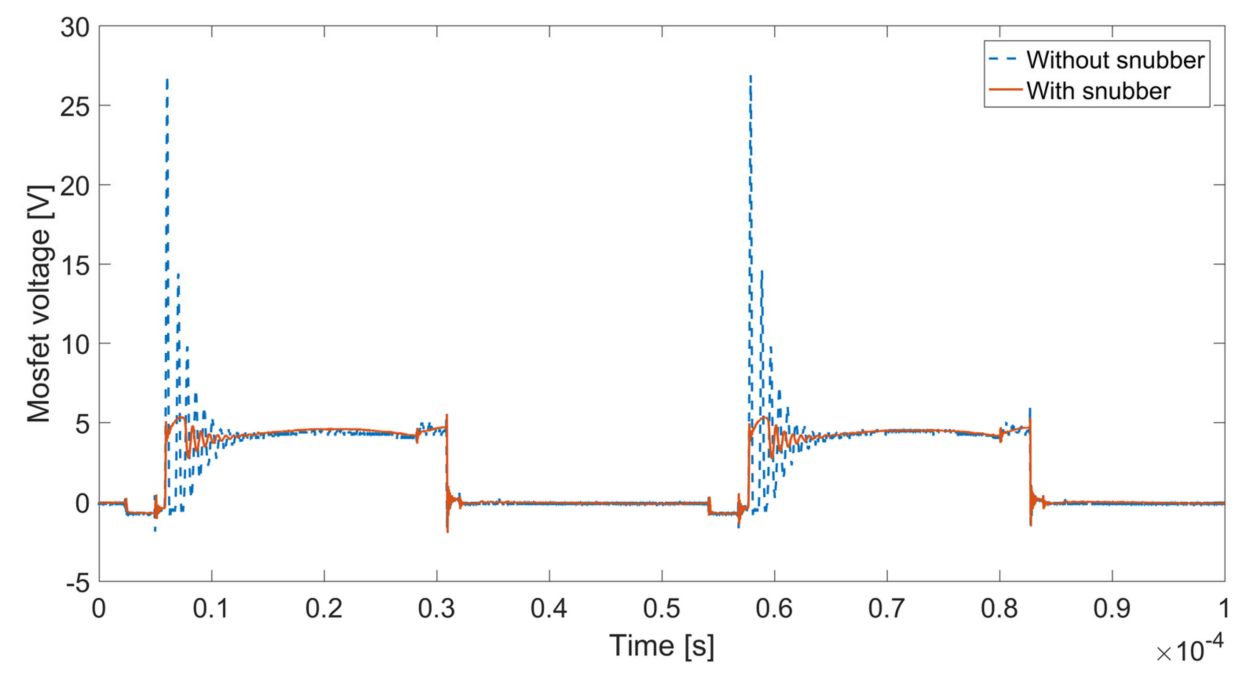

Figure 10. MOSFET voltages without (dashed blue line) and with (continuous red line) the snubber circuit.

In the right-hand side of Figure 9, the output voltage time behavior at three frequencies is shown. Again, a very good agreement between measurements and simulations has been obtained. When working with a frequency less than the soft switching frequency, the output voltage presents a high harmonic content. The harmonic distortion strongly decreases at the soft switching frequency and almost disappears when working beyond this value.

The working frequency influences the overall generator efficiency too. An evaluation of this important parameter, given by the ratio between the discharge average power and the DC input power, has been carried out. Both reactors already used to obtain the voltage frequency response presented in Figure 8 have been utilized for this purpose. As already mentioned, the first reactor is a surface DBD with an equivalent load capacitance of $15 \mathrm{pF}$, the second one is a volumetric DBD with an equivalent capacitance of $120 \mathrm{pF}$. In order to maintain the average power feeding both discharges to a constant value, $170 \mathrm{~W}$ for the volumetric reactor and $12 \mathrm{~W}$ for the surface one, input DC voltage has been decreased by increasing the switching frequency. Average discharge power has been evaluated with the Q-V Lissajous technique mentioned above. For both reactors, switching frequency has been varied in a range comprising soft switching and resonance frequencies. Switching frequency has been varied with steps of $1 \mathrm{kHz}$, and according to results shown in Figure 8, it has been increased from 27 to $44 \mathrm{kHz}$ for the surface DBD reactor ( $15 \mathrm{pF}$ equivalent load), and from 12 to $23 \mathrm{kHz}$ for the volumetric one (120 $\mathrm{pF}$ equivalent load).

The generator efficiency as a function of the switching frequency is shown in Figure 11 for both reactors. Soft switching and resonance frequency $\left(f_{s s}\right.$ and $f_{\text {res }}$, respectively) are displayed in the figure for both reactors. The efficiency trend is quite similar for both loads. It is possible to notice that, by working below the soft switching value, quite low efficiency is measured. At the soft switching frequency, a considerable increase of the efficiency is achieved. By further increasing the switching frequency, a plateau of the efficiency value is reached. Then, approaching the resonance frequency, 
the efficiency decreases. At the resonance frequency a sudden decrease of the efficiency is obtained. By further increasing the frequency this low value is maintained.

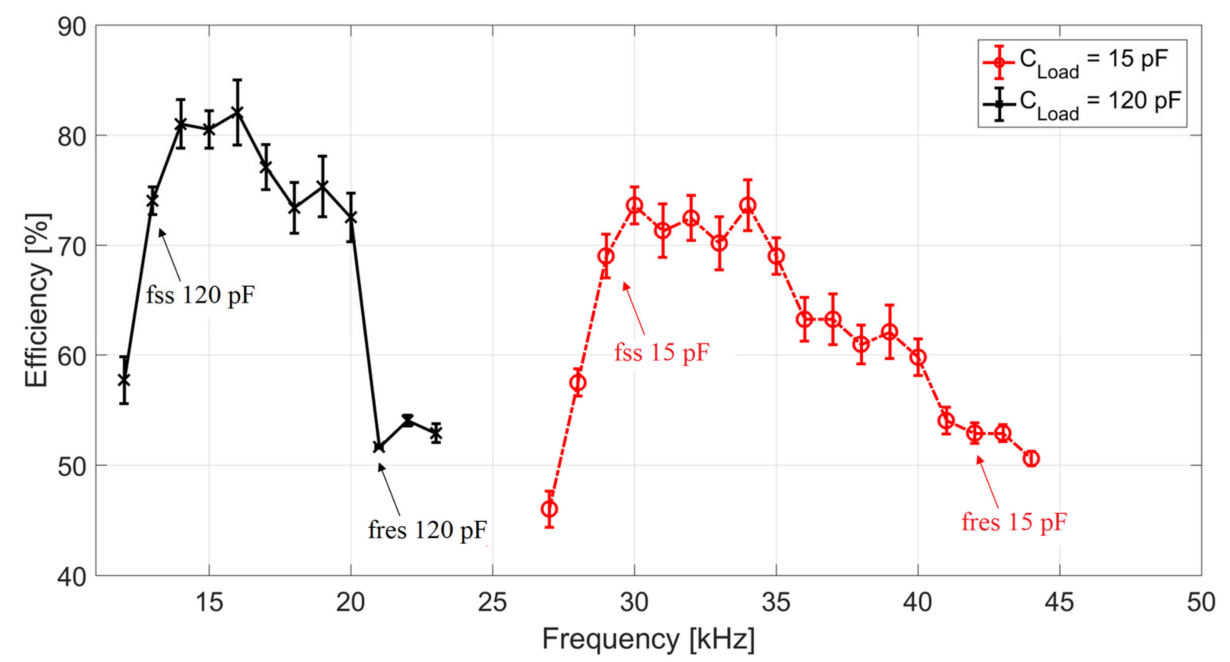

Figure 11. Generator efficiency as a function of the switching frequency.

A possible explanation of the efficiency trend, as a function of the working frequency can be given as follows. The main loss mechanisms are due to the Joule dissipation into windings and snubber components, and to iron losses. Below $f_{s s}$, snubber and iron losses dominate because of the relevant MOSFET overvoltages suppressed by snubbers and the important harmonic content owned by the output voltage (see right-hand side of Figure 9 a). Working at $f_{s s}$, both snubber and iron losses are strongly decreased. The Joule heating into windings starts to increase as the bus DC current increases. By a further increase of the frequency, iron losses decrease further as the output voltage's maximum value and its harmonic content both decrease. Thus, the high efficiency plateau is achieved. With a working frequency close to $f_{\text {res }}$, a strong increase of the winding current occurs. Therefore, a considerable Joule heating is generated. For frequencies equal to or lower than $f_{\text {res }}$, the Joule heating into windings and snubber dominate the losses, leading to a severe efficiency decrement. Loss mechanisms already described can be considered to explain differences in the efficiency trends for the two reactors as well. When average power feeding the surface discharge is more than an order of magnitude lower with respect to that supplying volumetric reactor, it is possible to affirm that iron losses are predominant in the surface reactor, especially in the low frequency range. As a matter of fact, these losses are related with the applied voltage value and not related with the current flowing into windings. This consideration could explain the lower value in the high efficiency plateau observed beyond soft switching frequency. On a parallel plane the decrement in efficiency for the surface reactor does not take place in such an abrupt way as it happens for the volumetric discharge. This could be related to a lower Joule heating effect taking place in the windings because of the lower average power delivered to the surface DBD.

Figure 11 shows the optimal frequency range at which the generator works. This range is between $14-16 \mathrm{kHz}$ for the volumetric reactor and between $30-34 \mathrm{kHz}$ for the surface one, corresponding to the plateau with high efficiency. On the other hand, this range guarantees both limited MOSFET overvoltages and a low harmonic content of the supply output voltage (Figure 9). The best working frequency, centered with respect to the high efficiency plateau region, can be found by means of the following empirical expression:

$$
f_{s s}+\left(f_{\text {res }}-f_{s s}\right) / 4 \text {. }
$$




\section{Self-Tuning Control Strategy}

In the previous section the definition and the evaluation of the best working frequency has been defined. This value can be automatically selected following the control strategy described below.

When a new load is connected to high-voltage terminals, an input DC voltage less than $1 \mathrm{~V}$ is set. Thus, the micro-controller performs a frequency scan and measures the output voltage corresponding to each frequency. The low input DC voltage guarantees limited high-voltage values avoiding reactor damages. For each frequency, the maximum value of the output voltage, and the corresponding fast Fourier transform (FFT) of the signal are calculated. The maximal value of maximal voltages for all frequencies corresponds to the resonance frequency (see Figure 7).

The FFT is calculated with a native Arduino library and allows finding the soft switching frequency. In the right-hand side of Figure 9, output voltages with frequencies less than, equal to and greater than the soft switching value have been shown. Normalized FFTs of these signals, determined by means of the micro-controller, are displayed in Figure 12.
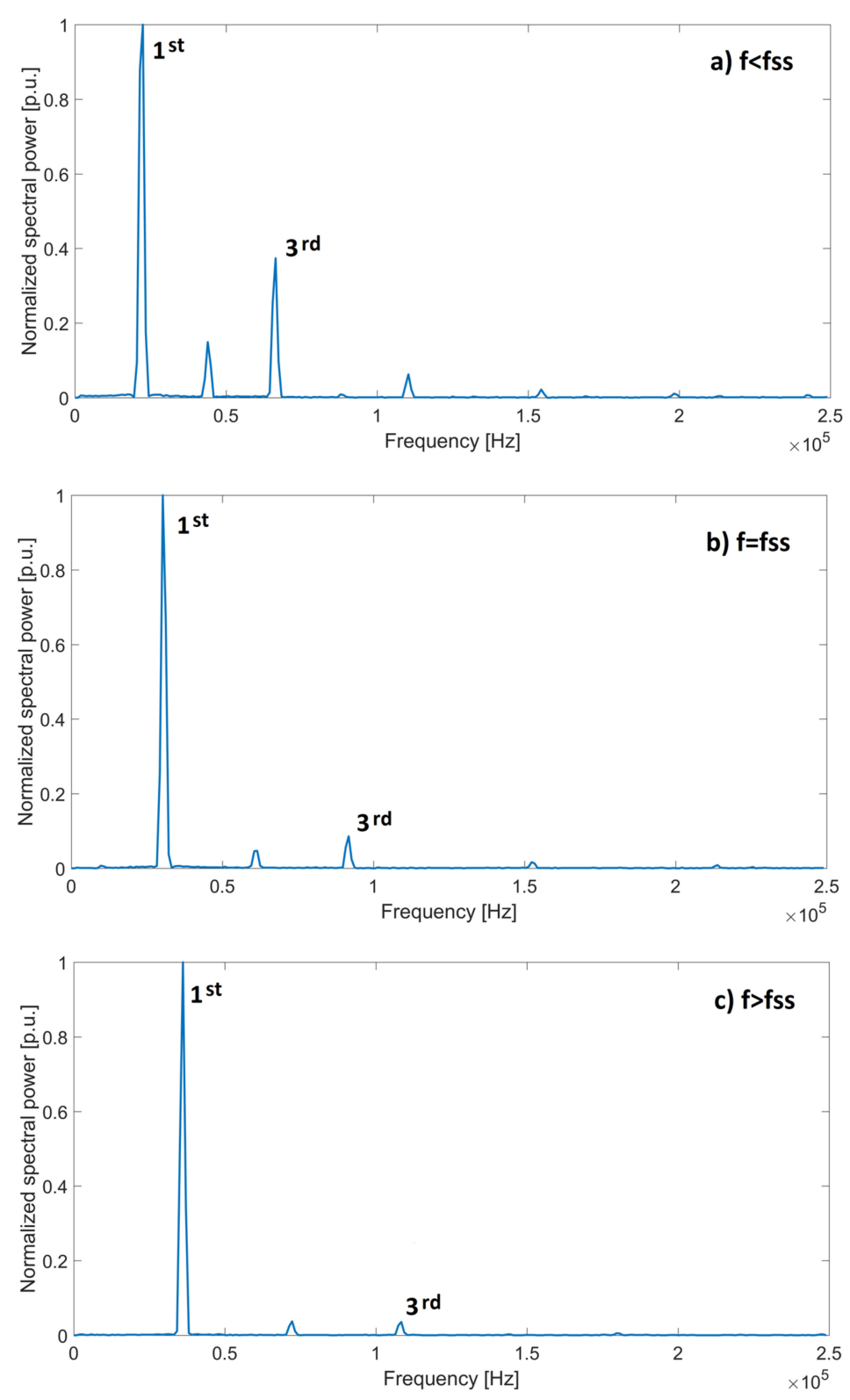

Figure 12. Fast Fourier transform (FFT) of the output voltage signals of Figure 9. 
The voltage harmonic content is higher for low frequencies and decreases approaching the resonance value. The ratio between first and third harmonic can be utilized by the micro-controller to determine the soft switching frequency. For the supply generator described in this work this ratio corresponds to 11 .

The time used by the micro-controller for the frequency scan is about $5 \mathrm{~s}$. After this procedure the soft switching frequency and the resonance frequency are known, and the micro-controller determines the best working frequency by means of the expression given in Equation (4).

After this initial self-tuning routine, the DC input is increased to reach the desired output voltage. The micro-controller measures the high voltage $V_{\text {out }}$ obtained and charge $Q_{m}$. Thus, the average power supplied to the discharge is calculated. About $5 \mathrm{~ms}$, of which $2 \mathrm{~ms}$ are for the sampling procedure and $3 \mathrm{~ms}$ are for the calculations, are used for the evaluation of the average output power. Therefore, a quasi-real-time evaluation of most important parameters of the discharge are available for the user and the optimal frequency and working voltage can be utilized.

\section{Conclusions}

In this work, a high-voltage, high-frequency sinusoidal power supply generator for a DBD reactor has been considered. The generator can produce sinusoidal voltages with amplitudes up to $20 \mathrm{kV}$, frequencies in the range of $10-60 \mathrm{kHz}$, and output average powers up to $200 \mathrm{~W}$. This power source is equipped with on-board diagnostics and is controlled by an Arduino DUE micro-controller. The main advantages of this generator are:

- The self-tuning of the switching frequency, which minimizes the components' stress and maximizes the overall efficiency.

- The modulation of the output voltage with on/off cycles (duty cycle condition), to maximize plasma efficacy depending on the application considered.

- A quasi-real-time evaluation of the high voltage and average power supplying the discharge, without the use of an expensive external measurement setup.

These features make this power supply versatile, economical and usable without external probes. Moreover, the evaluation of the average power in a quasi-real-time way will allow power control. This will lead to more accurate and efficient plasma treatments and processes in the industrial, biological and agri-food fields. The estimation of the dynamics related to this power control is currently under study. An increase of the overall generator efficiency is currently under development too, by properly sizing components and windings, and by optimizing transformer windings' arrangement [29].

Author Contributions: Conceptualization, G.N.; methodology, G.N.; validation, G.N.; investigation, G.N.; writing—original draft preparation, G.N., M.R.; writing—review and editing, G.N., M.R.; visualization, G.N., M.R.

Funding: This research received no external funding.

Conflicts of Interest: The authors declare no conflict of interest.

\section{References}

1. Kogelschatz, U. Dielectric-barrier Discharges: Their History, Discharge Physics, and Industrial Applications. Plasma Chem. Plasma Process. 2003, 23, 1-46. [CrossRef]

2. Rooth, J.R. Industrial Plasma Engineering: Volume 2: Applications to Nonthermal Plasma Processing; CRC Press: Boca Raton, FL, USA, 2001.

3. Fridman, A.; Kennedy, L.A. Plasma Physics and Engineering; CRC Press: Boca Raton, FL, USA, 2004.

4. Bernhardt, T.; Semmler, M.L.; Schäfer, M.; Bekeschus, S.; Emmert, S.; Boeckmann, L. Plasma Medicine: Applications of Cold Atmospheric Pressure Plasma in Dermatology. Oxidative Med. Cell. Longev. 2019, 2019, 1-10. [CrossRef] [PubMed]

5. Weltmann, K.-D.; von Woedtke, T. Plasma medicine - Current state of research and medical application. Plasma Phys. Control. Fusion 2017, 59, 014031. [CrossRef] 
6. Kim, H.-H.; Kim, H. Nonthermal Plasma Processing for Air-Pollution Control: A Historical Review, Current Issues, and Future Prospects. Plasma Process. Polym. 2004, 1, 91-110. [CrossRef]

7. Foster, J.E. Plasma-based water purification: Challenges and prospects for the future. Phys. Plasmas 2017, 24, 055501. [CrossRef]

8. Wagner, H.-E.; Brandenburg, R.; Kozlov, K.; Sonnenfeld, A.; Michel, P.; Behnke, J. The barrier discharge: basic properties and applications to surface treatment. Vacuum 2003, 71, 417-436. [CrossRef]

9. Vandenbroucke, A.M.; Morent, R.; De Geyter, N.; Leys, C. Non-thermal plasmas for non-catalytic and catalytic VOC abatement. J. Hazard. Mater. 2011, 195, 30-54. [CrossRef] [PubMed]

10. A Borghi, C.; Cristofolini, A.; Grandi, G.; Neretti, G.; Seri, P. A plasma aerodynamic actuator supplied by a multilevel generator operating with different voltage waveforms. Plasma Sources Sci. Technol. 2015, 24, 45018. [CrossRef]

11. Fridman, A. Plasma Chemistry; Cambridge University Press: Cambridge, UK, 2008.

12. Rodríguez, A.; Rosal, R.; Perdigón-Melón, J.A.; Mezcua, M.; Agüera, A.; Hernando, M.D.; Letón, P.; Fernández-Alba, A.R.; García-Calvo, E. Ozone-Based Technologies in Water and Wastewater Treatment. In The Handbook of Environmental Chemistry; Springer: Berlin/Heidelberg, Germany, 2008.

13. Bao, A.; Utkin, Y.G.; Keshav, S.; Lou, G.; Adamovich, I.V. Ignition of Ethylene-Air and Methane-Air Flows by Low-Temperature Repetitively Pulsed Nanosecond Discharge Plasma. IEEE Trans. Plasma Sci. 2007, 35, 1628-1638. [CrossRef]

14. Opaits, D.F.; Likhanskii, A.V.; Neretti, G.; Zaidi, S.; Shneider, M.N.; Miles, R.B.; Macheret, S.O. Experimental Investigation on Dielectric Barrier Discharge Plasma Actuators Driven by Repetitive High-Voltage Nanosecond Pulses with DC or Low Frequency Sinusoidal bias. J. Appl. Phys. 2008, 104, 043304. [CrossRef]

15. Benard, N.; Moreau, E. Role of the electric waveform supplying a dielectric barrier discharge plasma actuator. Appl. Phys. Lett. 2012, 100, 193503. [CrossRef]

16. Dragonas, F.A.; Neretti, G.; Sanjeevikumar, P.; Grandi, G. High-Voltage High-Frequency Arbitrary Waveform Multilevel Generator for DBD Plasma Actuators. IEEE Trans. Ind. Appl. 2015, 51, 3334-3342. [CrossRef]

17. Syakur, A.; Zaman, B.; Affif, F.; Nurjannah, S.; Nurmaliakasih, D.Y. Application of dielectric barrier discharge plasma for reducing Chemical Oxygen Demand (COD) on industrial rubber wastewater. In Proceedings of the 2016 3rd International Conference on Information Technology, Computer, and Electrical Engineering (ICITACEE), Semarang, Indonesia, 19-20 October 2016; pp. 1-5.

18. Ponce-Silva, M.; Aguilar-Ramirez, J.; Beutelspacher, E.; Calderon, J.M.; Cortés, C. Single-Switch Power Supply based on the Class E Shunt Amplifier for Ozone Generators. 2007 IEEE Power Electronics Specialists Conference 2007, 1380-1385.

19. Alonso, J.M.; Ordiz, C.; Gacio, D.; Ribas, J.; Calleja, A.J. Closed-loop Regulated Power Supply for Ozone Generation based on Buck Converter and Current-Fed Push-pull Resonant Inverter. In Proceedings of the 2009 13th European Conference on Power Electronics and Applications, Barcelona, Spain, 8-10 September 2009.

20. Gao, Y.; Liu, K.; Fu, R.; Sun, Y.; Yan, P. Development of dielectric barrier discharging power supply. In Proceedings of the 12th International Conference on Gas Discharge Plasmas and Their Applications, Tomsk, Russia, 6-11 September 2015.

21. Amjad, M.; Salam, Z.; Facta, M.; Mekhilef, S. Analysis and Implementation of Transformerless LCL Resonant Power Supply for Ozone Generation. IEEE Trans. Power Electron. 2013, 28, 650-660. [CrossRef]

22. Borghi, C.A.; Cristofolini, A.; Neretti, G.; Seri, P.; Rossetti, A.; Talamelli, A. Duty cycle and directional jet effects of a plasma actuator on the flow control around a NACA0015 airfoil. Meccanica 2017, 52, 3661-3674. [CrossRef]

23. Güler, A.A.; Seyhan, M.; Akansu, Y.E. Effect of signal modulation of dbd plasma actuator on flow control around naca 0015. J. Therm. Sci. Technol. 2018, 38, 95-105.

24. Simek, M.; Pekarek, S.; Prukner, V. Influence of Power Modulation on Ozone Production Using an AC Surface Dielectric Barrier Discharge in Oxygen. Plasma Chem. Plasma Process. 2010, 30, 607-617. [CrossRef]

25. Ma, T.; Jiang, H.; Liu, J.; Zhong, F. Decomposition of Benzene Using a Pulse-Modulated DBD Plasma. Plasma Chem. Plasma Process. 2016, 36, 1533-1543. [CrossRef]

26. Circuit Design Tools \& Calculators. Available online: http://www.linear.com/designtools/software/\#LTspice (accessed on 3 June 2018). 
27. Falkenstein, Z.; Coogan, J.J. Microdischarge behaviour in the silent discharge of nitrogen-oxygen and water-air mixtures. J. Phys. D Appl. Phys. 1997, 30, 817-825. [CrossRef]

28. Neretti, G.; Cristofolini, A.; Borghi, C.A.; Gurioli, A.; Pertile, R. Experimental Results in DBD Plasma Actuators for Air Flow Control. IEEE Trans. Plasma Sci. 2012, 40, 1678-1687. [CrossRef]

29. Bonnin, X.; Piquet, H.; Diez, R.; Florez, D. Designing the high voltage transformer of power supplies for DBD: Windings arrangment to reduce the parasitic capacitive effects. In Proceedings of the 2013 15th European Conference on Power Electronics and Applications (EPE), Lille, France, 2-6 September 2013; pp. 1-9.

(C) 2019 by the authors. Licensee MDPI, Basel, Switzerland. This article is an open access article distributed under the terms and conditions of the Creative Commons Attribution (CC BY) license (http://creativecommons.org/licenses/by/4.0/). 